\title{
Environmental sustainability: assessment criteria
}

\author{
Vladimir Sulimin, Vladislav Shvedov and Maya Lvova \\ Ural State University of Economics, Yekaterinburg, Russia
}

\begin{abstract}
Providing conditions for sustainable development is a fundamental task of human civilization. An important aspect of the current activities of modern society, which do not harm future generations, is the preservation of the structure and functions of the ecological system under the influence of various external and internal factors on it. an important aspect of ensuring the sustainable functioning and development of objects of animate and inanimate nature as key factors of favorable habitat and human activity is an effective assessment of the state of the ecosystem. The article discusses modern methods of environmental monitoring, criteria for qualitative data analysis aimed at improving environmental management technologies.
\end{abstract}

\section{Introduction}

The indicator of the state's ecological stability comprises several parameters, including: the state of the ecosystem, the ecological health of citizens, the level of ecological stress, social opportunities, the country's international activity in nature protection and conservation. $[2, \mathrm{p} .180]$.

We achieve environmental stability by improving the quality of resource use, introducing technologies that are safe for the surrounding world, structural transformations in the economy and environmental management, and the competent use of industrial waste.

The improvement of the level of environmental safety of society promotes improvement of health, increase in life expectancy of the population through the implementation of a policy of a healthy lifestyle.

Cleaning of territories from pollution left by previous generations, competent waste management, prevention of emergencies in the ecological system, regular environmental protection activities, implementation of sustainable development programs minimize the disruption of the natural balance because of human activities.

As part of the transition to environmental sustainability, countries preserve the natural environment, landscapes, and biological diversity of the ecosystem.

The specificity of the life of modern human society from the point of view of ecology is as follows [3, p.136]. 


\section{Methods and materials}

By exploiting non-recoverable minerals and fossil fuels, people do not rebuild them. Alternative energy sources of low capacity and resources with a low natural rate of renewal seem to be a weak substitute for depleting resources, which will become a serious obstacle to sustainable development.

The lack of waste-free production technologies, the transition of energy into heat, which violates the thermal balance of the Earth, the burning of oxygen reserves due to the combustion of gas, oil, coal, soil pollution with metal residues lead to the fact that the planet cannot cope with the processing of harmful substances on land, in water and in the air ...

Environmental activity of waste disposal is becoming only a form of their transfer from one toxic form to another - potentially dangerous for future generations.

People need to equitably develop and maintain every element of the ecological system to ensure environmental sustainability. It is unacceptable to keep silent about environmental problems on a global scale because the next generations of people will have to solve them in conditions of severe limited time, space and resources [4, p.122].

\section{Results and discussions}

The first stage of activities to improve the system for ensuring environmental sustainability is a competent assessment of the state of the environment. Based on the results of the assessment, we build a procedure for the consistent implementation of measures to preserve nature and a sustainable environment in the most important areas of human life - legislative, managerial, technological, economic, educational.

It is necessary to consider and predict changes in the environment to prevent negative environmental consequences. At the global level of international cooperation, this allows, for example, to keep the state of the ozone layer under control. Within the framework of the national observation system, the state of living and non-living natural objects is assessed in the national interests. Systematic observations in regions with a problematic ecological situation prevent its further deterioration. Local monitoring gets an excellent result in the areas of operation of enterprises that are especially hazardous to the environment. We use background observations for areas where there is no economic activity. The observation system includes studies of sources and factors of impact on the environment, the study of the state of the biosphere [1, p. 17].

Scientists are studying the effect of chemical, radioactive, thermal, electromagnetic, noise pollution on public health, urbanized environment, atmosphere, hydrosphere, soil.

Assessment of the state of the human habitat, biological communities is carried out to identify deviations, predict the consequences, develop a strategy for eliminating the causes of deviations.

Key indicators of environmental observations are: a) compliance of the state of the environment with international and national standards for anthropogenic impact; $b$ ) the state of the environment after human exposure to its components; c) the effectiveness the negative impact of economic activities of people on the world around them.

Knowledge of the general picture of the state of nature is very important for society. The state of nature includes the level of pollution of the atmosphere, surface waters, territorial seas, shelf, outer space in the near-earth part. The actual and predicted state of the natural environment affects the economic, economic life of society, the daily life of the population. Forecasts of meteorological conditions play an important role in preventing negative impact on the population, which makes it possible to respond promptly to situations by which the dispersion of emissions of harmful impurities in the atmosphere and the movement of water masses caused by accidents are delayed [5, p. 75]. 
Tracking the quality of drinking water, air in residential and industrial premises, the level of human morbidity caused by negative environmental effects contributes to improving the quality of environmental protection.

In studying the state of the environment, it is important to determine the compliance of human economic activities with environmental requirements in order to prevent adverse effects on nature, which may result in negative social and economic consequences. Conclusions about the possibility or impossibility of carrying out such activities can be made by allowed state structures and public organizations based on studying the project documentation. This form of preventive control, according to statistical data, saves significant money on the elimination of the negative consequences of environmentally hazardous economic activities; allows you to comply with environmental law and order, ensuring the protection of the right of any individual to a healthy environment; can be used as evidence in resolving environmental disputes, representing important information about the world around.

It based competent nature management on an effective socio-economic assessment of natural resources and secondary raw materials - quantitative and qualitative accounting. All data on water, land, forest resources of the country, objects of the animal world are collected in a single official, systematized code based on periodic and regular observations - the state cadastre, designed to ensure the rational use, protection and reproduction of resources $[7$, p.262].

The information basis of state cadastres is:

- the location of industrial facilities in various sectors of the national economy that significantly pollute the environment;

- the chemical composition of soils, waters;

- specifics of land use;

- population density;

- the content of the soil, landscape, ecological maps;

- ecological characteristics of industrial and agricultural enterprises.

We need this information to determine the following types of zones: a) prohibited; $b$ ) protective; c) security; d) agro-ecological; e) contaminated. The first includes reserves, green areas, the second - sanitary protection areas between livestock farms, production facilities and settlements, coastal strips), the third - non-contaminated, non-degraded lands affected by erosion, washed away soils, the fourth - strongly acidic, highly alkaline soils, areas of soil contaminated with heavy metals and pesticides.

Environmentally balanced nature management involves predicting negative environmental consequences associated with drainage and irrigation of soils, water pollution with physical compounds and nutrients. Based on a qualitative forecast, on-farm specialization is specified, yield is calculated, and environmental protection measures are developed [6, p.65].

All the work of ecology researchers should be based on a systematic approach to study the variety of connections between ecosystem elements, their properties, subordination, the specifics of dynamic equilibrium, the ability to withstand environmental changes.

Within the framework of a systematic approach, we determine the composition of the ecosystem, the distinctive features of the environmental objects affecting it. We establish internal and external connections, the conditions for the existence of many organisms, their interaction with inanimate components, natural and climatic conditions, seasonal, annual, long-term dynamics.

We can use biological models to study living objects from organisms created in laboratory conditions, with the help of which the influence of a particular factor on living nature is predicted. 
Modeling the physical, biological, biochemical elements of a bio-system as the basis for the scientific analysis of systemic ecology can create simplified models similar to the original for studying the influence of various external and internal factors on them, predicting evolutionary phenomena in ecological systems for their further improvement.

Effective environmental quality control based on clear assessment criteria prevents natural and anthropogenic changes in the natural environment that cause significant damage to the economic and social spheres of society.

\section{References}

1. A.I. Bedritsky, Proceedings of VNIIGMI-MCD 184, 5 (2019)

2. O.V. Borisova, Actual problems of economics and management at mechanical engineering enterprises, oil and gas industry in an innovation-oriented economy 1, 177 (2020)

3. S.A. Vorontsov, A.V. Ponedelkov, T.A. Nuvakhov, Science and Education: Economy and Economy; law and administration 3 (82), 134 (2017)

4. M.E. Grigorian, A.N. Semenova, Akademicheskaya publitsistika 12, 124 (2017)

5. E. D. Kopytova, Izvestiya vysshikh uchebnykh zavedeniy. Ser.: Ekonomika, finansy i upravleniye proizvodstvom 3 (33), 74 (2017)

6. A.A. Solovyanov, State Audit. Right. Economy 1, 64 (2017)

7. E.V. Shmykova, Checking the compliance of regulatory legal acts of the constituent entities of the Russian Federation with federal legislation in terms of exercising the powers delegated to them in the field of state environmental expertise. Proceedings of the All-Russian Research Institute for Environmental Protection for 2019. Moscow: VNII Ecology, 260 (2019)

8. F.F. Adedoyin, A.A. Alola, F.V. Bekun, Science of the Total Environment 713 (2020). doi:10.1016/j.scitotenv.2020.136726

9. J. Amankwah-Amoah, J. of Cleaner Production 271 (2020). doi:10.1016/j.jclepro.2020.123000

10. R. Krishnan, R. Agarwal, C. Bajada, K. Arshinder, J. of Cleaner Production 242 (2020). doi:10.1016/j.jclepro.2019.118374

11. M. Murshed, Environmental Science and Pollution Research 27(29), 36254 (2020). doi:10.1007/s11356-020-09497-3

12. T.K. Panda, A. Kumar, S. Jakhar, S. Luthra, J.A. Garza-Reyes, I. Kazancoglu, S.S. Nayak, J. of Cleaner Prod. 243 (2019). doi:10.1016/j.jclepro.2019.118575

13. S. Saint Akadiri, A. Adewale Alola, G. Olasehinde-Williams, M. Udom Etokakpan, Science of the Total Environment 708 (2020). doi:10.1016/j.scitotenv.2019.134653

14. S.A. Sarkodie, S. Adams, P.A. Owusu, T. Leirvik, I. Ozturk, Science of the Total Environment 719 (2020). doi:10.1016/j.scitotenv.2020.137530

15. G. Saxena, D. Purchase, S.I. Mulla, C.D. Saratale, R.N. Bharagava, Phytoremediation of heavy metal-contaminated sites: Eco-environmental concerns, field studies, sustainability issues, and future prospects (2020). doi:10.1007/398_2019_24

16. H. Sun, M. Mohsin, M. Alharthi, Q. Abbas, J. of Cleaner Production 251, (2020). doi:10.1016/j.jclepro.2019.119519

17. M. Umar, X. Ji, D. Kirikkaleli, Q. Xu, J. of Environmental Management 271, (2020). doi:10.1016/j.jenvman.2020.111026 